\title{
Hunting stability of high-speed railway vehicles on a curved track considering the effects of steady aerodynamic loads
}

(C) The Author(s) 2015

Reprints and permissions: sagepub.co.uk/journalsPermissions.nav DOI: I0.1 I77//0775463/557| 986 jvc.sagepub.com

SAGE

\author{
Xiaohui Zeng, Han Wu, Jiang Lai and Hongzhi Sheng
}

\begin{abstract}
Aerodynamic loads may have effects on the hunting stability, and the factor of curved track makes it more complicated. Therefore, considering the steady aerodynamic loads generated by crosswind and airflow in the opposite advancing direction of train, the hunting stability of high-speed railway vehicle on a curved track is studied in this paper. The changes of gravitational restoring force and creep coefficients which are caused by aerodynamic loads are considered, and the change of equilibrium position due to aerodynamic loads, centrifugal force and the factor of curved track is also in consideration. A mathematical model of a high-speed railway vehicle during curve negotiation with aerodynamic loads is set up. A program based on the model is written and verified. Using this program, the linear critical speed considering the effects of aerodynamic loads is determined by the eigenvalue analysis. This paper investigates the critical speeds in three aerodynamic conditions. Considering the aerodynamic loads, the dependence of critical speed on curve radius and superelevation is analyzed, and the impact of aerodynamic loads on instability mode is analyzed as well. In addition, this paper obtains the dominant factors affecting critical speed and the variation tendency of critical speed with primary longitudinal stiffness by orthogonal experiments. The results show that the critical speed decreases or increases while the wind is blowing to outer rail or inner rail respectively. The aerodynamic loads produce obvious effects on the instability mode. The variation tendency of critical speed dependence on curve radius in the conditions with aerodynamic loads keeps consistent with the case without aerodynamic loads. It is seen from the orthogonal experiments that, aerodynamic loads and curve radius are the dominant factors affecting linear critical speed of vehicle on a curved track, and the linear critical speed decreases with the increasing of primary longitudinal stiffness.
\end{abstract}

\section{Keywords}

Hunting stability, aerodynamic loads, curved track, linear critical speed, instability mode, orthogonal experiments

\section{Introduction}

The hunting stability on a straight track or curved track is an important index for the behavior of railway vehicles. The hunting stability on a curved track is different from that on a straight track, so studies should be carried out respectively. In consideration of complex actions of many factors, the hunting motion of railway vehicles has a strong nonlinear dynamic character. However, the linear stability is not only the basis of nonlinear research, but also the basic stability feature of vehicle system. For example, the linear critical speed which reflects the ability for the vehicle to keep stable on the track can be obtained from the analysis of linear stability. For the purpose of getting linear critical speed and its variation trend with parameters, one should linearize the dynamic equations of vehicle system at the equilibrium position and perform the eigenanalysis in the neighborhood of the equilibrium position. While the vehicle is negotiating a curved track, centrifugal force and factor of curved track can make the equilibrium position changed a lot, consequently, the contact parameters of wheel/rail and creep relationship change a lot compared with the case on a straight track. Hence,

Institute of Mechanics, Chinese Academy of Sciences, China

Received: 13 June 20I4; accepted: 8 January 2015

Corresponding author:

Xiaohui Zeng, Institute of Mechanics, Chinese Academy of Sciences, No.I5 Beisihuanxi Road, Beijing 100190, China.

Email: zxh@imech.ac.cn 
the equilibrium position of vehicle on a curved track is a must before evaluating the eigenvalues of hunting stability (Zeng, 2001).

Studies about hunting stability of railway vehicles have been carried out a lot before, which includes hunting stability on straight track and curved track. The major method adopted to study the linear stability is linearizing the nonlinear dynamic equations of vehicle system at the equilibrium position, and determining the linear stability of the equilibrium position of nonlinear system by the eigenvalues of the linearized equations. Kim et al. (2011), Cheng (2012) and Cheng and Lee (2010) studied the linear stability characters of railway vehicle on a straight track by using this method, and analyzed the influence of suspension parameters on linear critical speed. Based on this theory, Cheng et al. (2009), Lee and Cheng $(2005,2006)$ and Liu et al. (2005) evaluated the linear critical speed of railway vehicle on a curved track, then investigated the influence of suspension parameters, curve radius and other factors on the linear critical speed. Wang and Liao (2010) studied the advantage of a mechanical structure to lateral stability according to this method. Dukkipati and Narayana Swamy (2001a, 2001b) studied the lateral stability of unconventional rail trucks, and investigated the compatibility of stability and curve performance.

Some researchers adopt both eigenvalue analysis and numerical integration to obtain limit cycles and bifurcation diagram in order to analyze the nonlinear stability. Zeng and Xu (1994), Zeng (2001), Zeng and Wu (2004) and Hirotsu et al. (1991) adopted these two methods, and obtained the linear and nonlinear critical speed on a straight and curved track, as well as the bifurcation diagrams. They analyzed the influence of suspension parameters, curve radius and other parameters on the hunting stability of a vehicle running on a curved track. Moreover, the methods of eigenvalue analysis and shooting method are also an usual way to obtain limit cycle and bifurcation diagram. Zeng (1996) and Dong et al. (2013) obtained the bifurcation diagrams of vehicle system by this way, what's more, Dong et al. (2013) performed a widely analysis on bifurcation characteristic of the China Railway High-speed $(\mathrm{CRH})$ vehicles. In addition, Zboinski and Dusza (2006, 2008, 2010, 2011) conducted a series of studies about non-linear stability on a curved track. They drawn the bifurcation diagram and analyzed the influence of suspension parameter, wheel-rail profile, rail cant and wheel-rail wear etc on the non-linear nonlinear characteristic.

Using high-speed train is the development tendency of worldwide railway transportation. So far, twenty thousand kilometers high-speed railway has been built. The maximum speed of railway trains becomes larger in recent years, such as the CRH380A train of China has reached $486.1 \mathrm{~km} / \mathrm{h}$. The increasing speed is not only maximum speed, but also the commercial operation speed which has reached $350 \mathrm{~km} / \mathrm{h}$. This commercial operation speed is equal to or even larger than the take-off speed of passenger aircrafts. Because aerodynamic force is proportional to the square of speed, the aerodynamic loads due to reverse air flow and cross wind in high-speed are much larger than that in low speed. This indicates that researchers should pay attention to the aerodynamic effects. Researchers have studied the aerodynamic actions in some respects. For instance, Baker (2010) and Baker et al. (2011) calculated the aerodynamic forces while the train was running and analyzed the influence of time period of cross wind on simulation method. He proposed a new method and calculated the dynamic response of train as well. Cheng et al. (2011) investigated the dynamic response of train when the cross wind was considered as forced loads; Yu et al. (2011) and Liu et al. (2011) calculated the dynamic response of car body and wheel-set. What's more, they analyzed the influence of unsteady aerodynamic forces on riding index. Suzuki et al. (2003) found that the aerodynamic characteristics of train/vehicles under cross winds depend on not only the shapes of the vehicles but also those of infrastructures. He made wind tunnel tests to evaluate aerodynamic characteristics of typical cases. Mao et al. (2011) performed research on the basis of the $\mathrm{CRH}$ train with several methods including theoretical analysis, model experiment, air fluid simulation analysis and multi-body system dynamics simulation. She investigated the aerodynamic characters about cross wind and the vehicle-track dynamics. She also conducted a study about safety control under cross wind. Cheli et al. (2006) and Baker et al. (2009) derived aerodynamic coefficients through experimental wind tunnel tests and aerodynamic admittance function, and developed a numerical model of the aerodynamic admittance function and verified. They also investigated the dynamic response of railway vehicle under aerodynamic forces.

The research about aerodynamic effects on railway vehicle mostly are getting aerodynamic force through numerical simulation or experimental method and analyzing the dynamic response of vehicle through considering the aerodynamic loads as forced actions. In fact, this research is about forced vibration. However, the hunting motion of railway vehicles under aerodynamic actions is a problem of self-excited vibration. Its mechanical mechanism is different from forced vibration. Forced vibration analysis cannot be used to illustrate the results of the characteristics of the selfexcited vibration. In other words, the existing forced vibration analysis on vehicle under aerodynamic loads 
is difficult to characterize the hunting stability of vehicles under aerodynamic loads, thus the hunting stability study of high-speed railway vehicle considering the effects of aerodynamic loads is needed.

It seems that few literature reports the research of hunting stability of high-speed railway vehicle considering aerodynamic loads. Zeng and Lai (2013) studied the hunting stability of high-speed vehicle on a straight track under aerodynamic loads, but the corresponding research on a curved track have not been seen. In fact, the aerodynamic loads can change wheel/rail normal forces, and then change the creep coefficients and gravitational restoring force. Consequently, parameters in the motion equations of vehicle dynamic system are changed (the natural characteristics of dynamic system are changed). Meanwhile, the equilibrium position of vehicle dynamic system can be changed by the aerodynamic loads, and this equilibrium position is different from that evaluated only considering constraints of curved track and centrifugal force. After considering these effects of aerodynamic loads, how the eigenvalues and eigenvectors of vehicles dynamic system will change, and how much they will change? How much the critical speed and instability mode of railway vehicle will change? What's the variation trend of the critical speed and instability mode in regard to parameters? There are many factors that affect the critical speed, including aerodynamic loads, curve radius, super-elevation and suspension parameters etc, and which one is the dominant factor. These questions are worthy of further study.

In summary, there are two points about the current research to explain. First, as for the hunting stability problems of railway vehicles on a curved track, the existing studies do not consider the impact of aerodynamic effects. Second, the current studies about aerodynamic effects on railway vehicles mostly simulate the aerodynamic forces and analyze the dynamic response of vehicles through considering these aerodynamic forces as forced actions. These studies are actually a problem of forced vibration. However, analysis on hunting motion of railway vehicles under aerodynamic actions is a problem of self-excited vibration. There are essential differences between these two problems. With the above consideration, problems about the hunting stability of high-speed railway vehicle on a curved track considering effects of steady aerodynamic loads are worthy of further study.

In order to solve the problem of multi-factorial experiment to distinguish the dominant factors and second factors, the orthogonal experiment method is utilized. By reasonable combination of factors, the orthogonal experiment can help to obtain the fluctuation of index with each factor using fewer experiments, and also find the dominant factors through the range analysis.
The analysis method of hunting stability of railway vehicles on a curved track under aerodynamic loads is provided in this paper. The authors write a computational program AHSHSRVCT based on this method. When compared the results of the program with those of the literature, good agreements are observed. On the basis of theoretical analysis and the computational program, the authors evaluate the equilibrium position of vehicle running on a curved track considering aerodynamic loads. After the equilibrium position is known, the authors evaluate the eigenvalues of the hunting stability and determine the linear critical speed. The critical speeds in the two conditions with aerodynamic loads and without aerodynamic loads are investigated. The influence of curve radius and super-elevation of track on the critical speed is analyzed when aerodynamic loads are considered, as well as the influence of aerodynamic loads on the instability mode. In addition, the calculation is performed according to the orthogonal experiment method. The dominant factors affecting the linear critical speed of vehicle on a curved track and the variation of critical speed with primary longitudinal stiffness are obtained.

\section{Theory}

\section{I. Vehicle system model}

Figure 1 is a schematic diagram of a dynamic model used for evaluating the hunting stability on a constant radius curve, where $v$ is the speed of the vehicle, and $R$ is the radius of the curved track. As shown in Figure 1, there is an angle between the local coordinate systems due to the curve. Figure 2 is the configuration of the railway vehicle dynamic system, where stiffness and damping elements have been incorporated into the suspensions. As shown in Figure 2, body/frame is connected by the second suspension, and frame/wheel is connected by the primary suspension. $C_{0}$ is the superelevation.

The numbers in Figure 2 represent suspension system: 1, 2: primary lateral and longitudinal stiffness; 3: primary vertical stiffness and damping; 4 : secondary lateral stiffness and damping; 5: secondary vertical stiffness and damping; 6: secondary lateral damper and 7 : secondary yaw damper.

The motion model of a high-speed railway vehicle with 17 degrees of freedom (DOFs) is set up when the hunting stability of railway vehicles negotiating a curved track is analyzed. Table 1 shows these 17 DOFs, they are expressed as $\mathbf{Y}_{\mathbf{1}}$.

There are lateral displacements $y_{h}$ of spring-damping connecting point of lateral damper and longitudinal displacements $y_{s}$ of spring-damping connecting point 


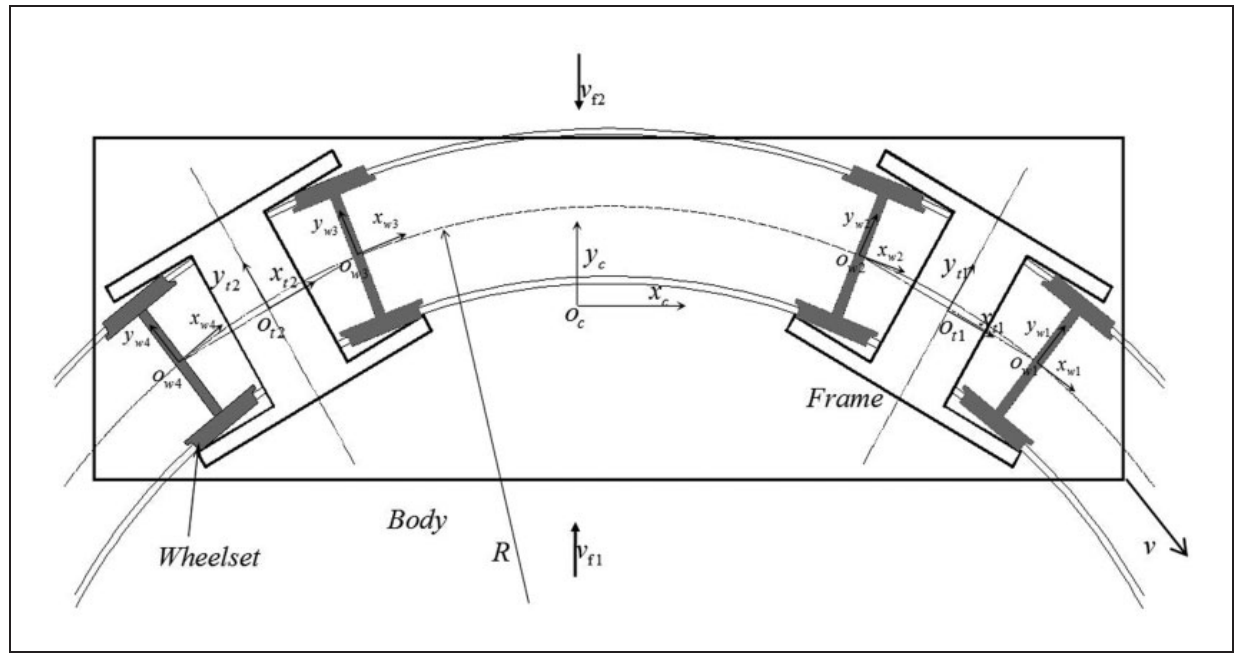

Figure I. Coordinate for vehicle during curve negotiation.

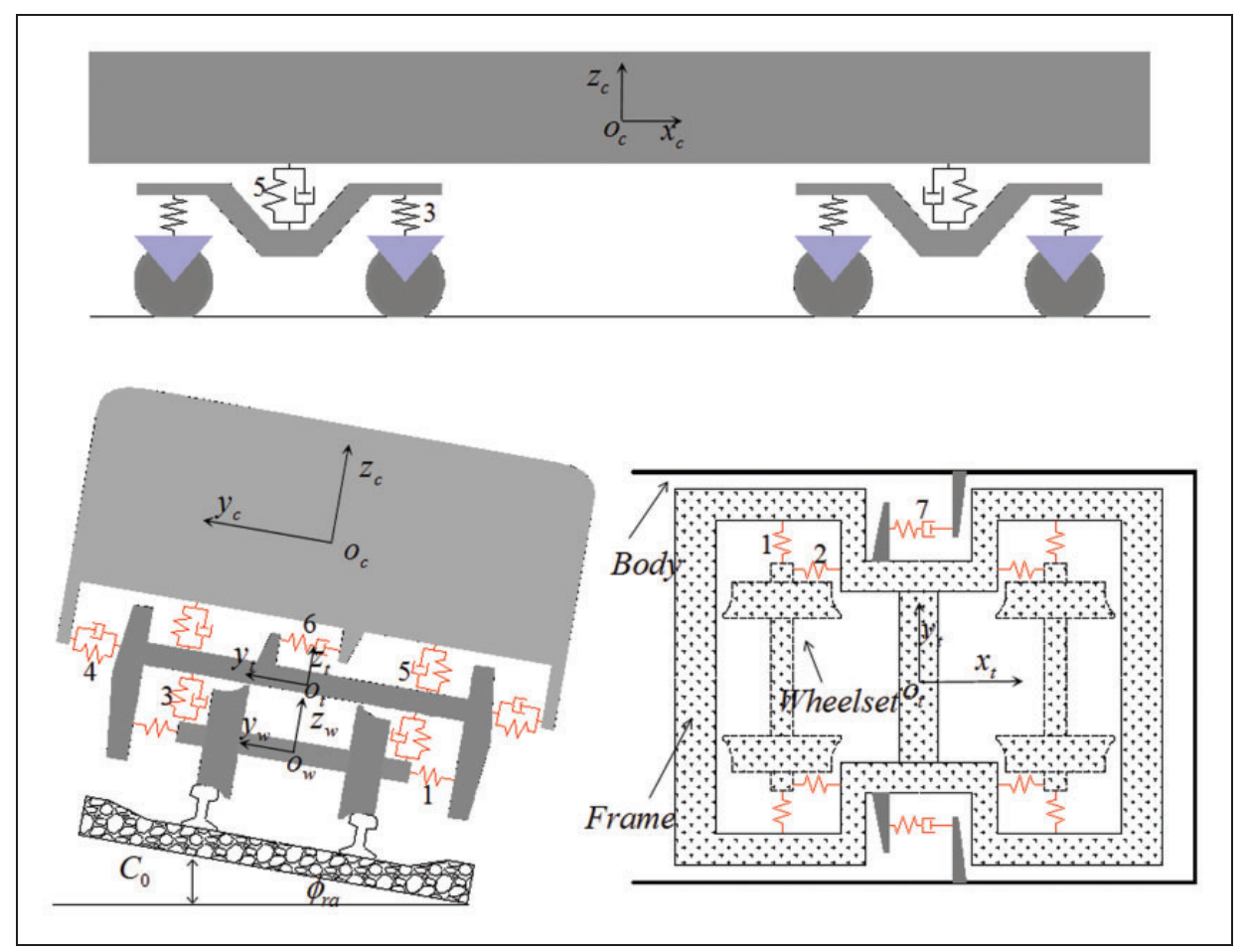

Figure 2. Configuration of the railway vehicle model.

Table I. The DOFs of vehicle.

\begin{tabular}{llll}
\hline Directions & Lateral & Roll & yaw \\
\hline Body & $Y_{c}$ & $\phi_{c}$ & $\psi_{c}$ \\
Frames $(i=1,2)$ & $Y_{t i}$ & $\phi_{t i}$ & $\psi_{t i}$ \\
Wheel-sets $(i=1 \sim 4)$ & $Y_{w i}$ & & $\psi_{w i}$ \\
\hline
\end{tabular}

of yaw damper. They can be expressed as $\mathbf{Y}_{\mathbf{2}}$, as shown in equation (1).

$$
\mathbf{Y}_{2}=\left[\begin{array}{llllll}
\mathrm{y}_{h L} & y_{h R} & y_{s L 1} & y_{s R 1} & y_{s L 2} & y_{s R 2}
\end{array}\right]^{T}
$$

As for the dynamic system of railway vehicle on a curved track under aerodynamic loads, the motion equations can be expressed as equation (2), where $C_{L}$, $C_{C}, M_{X}, M_{Y}$ and $M_{Z}$ are the coefficient of aerodynamic 
lift force, lateral force, overturning moment, pitch moment and yaw moment, respectively, $\mathbf{U}$ and $\mathbf{V}$ are velocity of wind and vehicle, and $\mathbf{P}_{\mathbf{g}}$ and $\mathbf{P}_{\mathbf{f}}$ denote the centrifugal force and aerodynamic force. Besides, $\mathbf{M}, \mathbf{C}$ and $\mathbf{K}$ are inertia matrix, damping matrix and stiffness matrix respectively. In equation (2), $\mathbf{C}_{1}\left(\mathbf{P}_{\mathbf{f}}, \mathbf{U}, \mathbf{V}\right.$, $\left.R, C_{0}, \mathbf{Y}, \dot{\mathbf{Y}}\right)$ and $\mathbf{K}_{1}\left(\mathbf{P}_{\mathbf{f}}, \mathbf{U}, \mathbf{V}, R, C_{0}, \mathbf{Y}, \dot{\mathbf{Y}}\right)$ show that damping matrix and stiffness matrix are affected by the aerodynamic loads and curved track, and the vibration system is a nonlinear system. As the hunting stability is analyzed, the aerodynamic loads are steady in this paper.

$$
\begin{aligned}
& {\left[\begin{array}{cc}
\mathbf{M}_{1} & 0 \\
0 & 0
\end{array}\right]\left\{\begin{array}{c}
\ddot{\mathbf{Y}}_{1} \\
\ddot{\mathbf{Y}}_{2}
\end{array}\right\}+\left[\begin{array}{cc}
\mathbf{C}_{1}\left(\mathbf{P}_{\mathbf{f}}, \mathbf{U}, \mathbf{V}, R, C_{0}, \mathbf{Y}, \dot{\mathbf{Y}}\right) & 0 \\
\mathbf{C}_{2} & \mathbf{C}_{3}
\end{array}\right]\left\{\begin{array}{c}
\dot{\mathbf{Y}}_{1} \\
\dot{\mathbf{Y}}_{2}
\end{array}\right\}} \\
& +\left[\begin{array}{cc}
\mathbf{K}_{1}\left(\mathbf{P}_{\mathbf{f}}, \mathbf{U}, \mathbf{V}, R, C_{0}, \mathbf{Y}, \dot{\mathbf{Y}}\right) & \mathbf{K}_{2} \\
\mathbf{K}_{3} & \mathbf{K}_{4}
\end{array}\right]\left\{\begin{array}{c}
\mathbf{Y}_{1} \\
\mathbf{Y}_{2}
\end{array}\right\} \\
& =\mathbf{P}_{\mathbf{f}}\left(C_{L}, C_{C}, C_{M x}, C_{M y}, C_{M z}, \mathbf{U}, \mathbf{V}\right)+\mathbf{P}_{\mathbf{g}}
\end{aligned}
$$

As shown in equation (2), there are obvious differences between the railway vehicle vibration system considering aerodynamic loads and that without aerodynamic loads. However, most business software cannot simulate such effects of aerodynamic loads on vibration system of railway vehicle.

Through coordinate transformation $\mathbf{X}=$ $\left[\begin{array}{lll}\dot{\mathbf{Y}}_{1} & \mathbf{Y}_{1} & \mathbf{Y}_{2}\end{array}\right]^{T}$, the second order differential equation (2) can be rewritten as equation (3).

$$
\frac{\mathrm{d} \mathbf{X}}{\mathrm{d} t}=\mathbf{F}(\mathbf{x})
$$

\subsection{Aerodynamic loads}

Under the aerodynamic actions, distributed pressure and shear stress on the vehicle body surface can form the resultant forces called aerodynamic drag force, aerodynamic lateral force and aerodynamic lift force $F_{i}(i=1 \sim 3)$ in three directions, namely the longitudinal, lateral and vertical direction, and the overturning moment around $\mathrm{x}$-axis, the pitch moment around $\mathrm{y}$ axis, the yaw moment around z-axis $M_{i}(i=1 \sim 3)$. They are expressed as equation (4).

$$
\begin{aligned}
F_{i} & =\frac{1}{2} \rho A C_{i}|\mathbf{V}+\mathbf{U}|^{2} \quad(i=1,2,3) \\
C_{1} & =C_{D}, \quad C_{2}=C_{L}, \quad C_{3}=C_{C} \\
M_{i} & =\frac{1}{2} \rho A L C_{M i}|\mathbf{V}+\mathbf{U}|^{2} \quad(i=1,2,3) \\
C_{M 1} & =C_{M x}, \quad C_{M 2}=C_{M y}, \quad C_{M 3}=C_{M z}
\end{aligned}
$$

The aerodynamic loads make the axle loads and contact normal forces changed, and then make the creep forces and restoring forces generated by gravity changed. Meanwhile, the equilibrium position of vehicle dynamic system can be also changed. Because of these effects of aerodynamic loads, the hunting stability of high-speed railway vehicle on a curved track changes. This paper mainly analyzes the hunting stability of railway vehicle during curve negotiations in the three aerodynamic conditions:

1. The aerodynamic actions are without consideration.

2. The wind blows to outer track along radial direction, as $v_{f 1}$ shown in Figure 1.

3. The wind blows to inner track along radial direction, as $v_{f 2}$ shown in Figure 1.

When a railway vehicle is negotiating a constant radius curve at a constant speed, the resultant velocity of wind velocity and reverse vehicle velocity is also constantly changing owing to the factor of curve, even if the wind direction does not change. That is to say, the relative angle of attack between the resultant velocity and vehicle velocity is constantly changing, so the aerodynamic coefficients are also constantly changing. However, assuming that the radius of curve is relatively large, and the length of curve is relatively small, the direction of velocity vector changes little after the railway vehicle passes the curve segment at a certain speed. What's more, the speed of high-speed railway vehicle is generally much larger than wind speed, so slightly direction change of vehicle velocity has less impact on the relative angle of attack. For example, the length of curved track is $500 \mathrm{~m}$, curve radius is $6000 \mathrm{~m}$, vehicle speed is $330 \mathrm{~km} / \mathrm{h}$, and wind speed is $10.7 / \mathrm{s}$. The velocity vector of vehicle is perpendicular to the velocity vector of wind at the starting point of the curve, so the relative angle of attack is $6.67^{\circ}$. When the vehicle is at the end point of the curve, the relative angle of attack is $6.58^{\circ}$. The relative angle of attack at the end of the curve varies by $1.3 \%$ from that at the start of the curve. Hence, the relative angle of attack and aerodynamic coefficients can be approximately considered as steady, and the wind velocity from distant flow field is always perpendicular to vehicle velocity. In other words, the two wind conditions investigated in this paper are meaningful.

\subsection{Wheel/rail contact relationship and the wheel/rail interactive forces}

2.3.I. Wheel/rail contact relationship. Wheel/rail contact relationship includes wheel-set rolling radius, contact angle, roll angle of wheel-set, transverse radius of wheel profile and transverse radius of rail profile etc. 
It can be considered as nonlinear functions of wheel-set lateral displacement $y_{w}$. Because the profiles of wheel and rail are composed of several irregular lines, the contact parameters are difficult to be expressed as explicit functions of $y_{w}$. Therefore, the profiles of wheel and rail are described as discrete point set in terms of $y_{w}$, the contact parameters are calculated using spline interpolation. The contact parameters are applied to calculate contact normal forces and nonlinear creep forces.

Considering that the flange contact rarely occurs on large radius track, the one-point tread contact assumption is adopted in this paper.

\subsubsection{Contact normal forces and gravitational restoring} force. The normal forces of wheel-rail contact point and the DOFs of vehicle are coupled with each other, and the normal forces are unknown values in the calculation. The normal forces can be evaluated by the motion equations of roll angle $\phi_{w}$ and vertical displacement $z_{w}$ of wheel-set, as shown in equation (5). Where subscript $L$ and $R$ represent left and right respectively, $N_{L}$ and $N_{R}$ are contact normal force, $\alpha_{L}$ and $\alpha_{R}$ are contact angle, $d_{z x}$ is half of lateral distance of axle box, $d_{0}$ is half of track gauge, $R_{L}$ and $R_{R}$ are wheel rolling radius, $F_{p z L}, F_{p z R}, f_{p z L}$ and $f_{p z R}$ are the variation of stiffness force and damping force of primary suspension, $F_{y L}$ and $F_{y R}$ are lateral creep forces, $M_{g x}$ is the gyroscopic moment around $\mathrm{x}$ axle of wheel-set.

$$
\begin{aligned}
& N_{L}\left(\mathbf{P}_{\mathbf{f}}, \mathbf{U}, \mathbf{V}, \mathbf{Y}, \dot{\mathbf{Y}}, \ddot{\mathbf{Y}}\right) \\
& =2 \cos \alpha_{L}\left(W+M_{w} \ddot{z}_{w}-F_{p z L}-F_{p z R}-f_{p z L}-f_{p z R}\right) \\
& +\frac{2 \cos \alpha_{L}}{d_{0}}\left(\begin{array}{l}
I_{w x} \ddot{\phi}_{w}-M_{g x}-d_{z x} F_{p z L}+d_{z x} F_{p z R} \\
-d_{z x} f_{p z L}+d_{z x} f_{p z R}-F_{y L} R_{L} \\
-F_{y R} R_{R}-R_{R} N_{R} \sin \left(\alpha_{R}-\phi_{w}\right) \\
+R_{L} N_{L} \sin \left(\alpha_{L}+\phi_{w}\right)
\end{array}\right) \\
& N_{R}\left(\mathbf{P}_{\mathbf{f}}, \mathbf{U}, \mathbf{V}, \mathbf{Y}, \dot{\mathbf{Y}}, \ddot{\mathbf{Y}}\right) \\
& =2 \cos \alpha_{R}\left(\begin{array}{l}
W \\
\left.+M_{w} \ddot{z}_{w}-F_{p z L}-F_{p z R}-f_{p z L}-f_{p z R}\right)
\end{array}\right. \\
& -\frac{2 \cos \alpha_{R}}{d_{0}}\left(\begin{array}{l}
I_{w x} \ddot{\phi}_{w}-M_{g x}-d_{z x} F_{p z L}+d_{z x} F_{p z R} \\
-d_{z x} f_{p z L}+d_{z x} f_{p z R}-F_{y L} R_{L} \\
-F_{y R} R_{R}-R_{R} N_{R} \sin \left(\alpha_{R}-\phi_{w}\right) \\
+R_{L} N_{L} \sin \left(\alpha_{L}+\phi_{w}\right)
\end{array}\right)
\end{aligned}
$$

The $\phi_{w}$ and $z_{w}$ are not independent, but constrained by the wheel-set contact relationships. There are values of DOFs in equation (5), and equation (5) is implicit. The normal forces are needed before calculating DOFs of vehicle through integral computation. Consequently, the contact normal forces need iterative calculation with DOFs of vehicle. In addition, $M_{g x}$ plays a role in the contact forces, seen in equation (5). The influence on contact forces can affect the equilibrium position of vehicle, correspondingly it affect the linearized equations of motion and hunting stability.

As shown in equation (5), $N_{L, R}\left(\mathbf{P}_{\mathbf{f}}, \mathbf{U}, \mathbf{V}, \mathbf{Y}, \dot{\mathbf{Y}}, \ddot{\mathbf{Y}}\right)$ represents the wheel/rail normal force which is affected by aerodynamic loads and DOFs. In fact, the expression of contact forces includes $\phi_{w}, z_{w}$ and suspension forces of primary suspension. In equation (2), DOFs and suspension forces are coupled with each other, thus $\phi_{w}, z_{w}$ and suspension forces of primary suspension are affected by aerodynamic loads. Take $F_{p z L}$ and $F_{p z R}$ in the first wheel-set for example, when the aerodynamic loads are out of consideration, $F_{p z L}$ and $F_{p z R}$ can be expressed as equation (6). Where $K_{p z}$ is vertical stiffness of primary suspension, $\phi_{t}$ and $\beta_{t}$ are roll angle and pitch angle of frame respectively, $d_{z x}$ half of lateral distance of axle box, and $l_{t}$ is half of longitudinal distance of axle box.

$$
F_{p z L, R}=K_{p z}\left( \pm d_{z x} \phi_{t} \mp l_{t} \beta_{t}\right)
$$

After considering aerodynamic actions, the aerodynamic loads affect the values of DOFs, and then the values of DOFs become functions of aerodynamic forces. Suspension forces become functions of aerodynamic forces too. Equation (6) can be rewritten as equation (7).

$$
\begin{gathered}
F_{p z L, R}=K_{p z}\left[ \pm d_{z x} \phi_{t}\left(C_{L}, C_{C}, C_{M x}, C_{M y}, C_{M z}, U, V\right)\right. \\
\left.\mp l_{t} \beta_{t}\left(C_{L}, C_{C}, C_{M x}, C_{M y}, C_{M z}, U, V\right)\right]
\end{gathered}
$$

Other terms in equation (5) are similar to $F_{p z L}$ and $F_{p z R}$, so aerodynamic loads can make the contact normal forces changed.

The gravitational restoring force can be calculated by contact normal forces, roll angle of wheel-set and contact angle, as shown in equation (8). It is obvious that aerodynamic loads can make the gravitational restoring force changed, that is to say, the natural characteristics of vehicle dynamic system are changed by the aerodynamic loads.

$$
\begin{aligned}
F_{\text {restoring }}= & N_{L}\left(\mathbf{P}_{\mathbf{f}}, \mathbf{U}, \mathbf{V}, \mathbf{Y}, \dot{\mathbf{Y}}, \ddot{\mathbf{Y}}\right) \cdot \sin \left(\alpha_{L}+\phi_{w}\right) \\
& -N_{R}\left(\mathbf{P}_{\mathbf{f}}, \mathbf{U}, \mathbf{V}, \mathbf{Y}, \dot{\mathbf{Y}}, \ddot{\mathbf{Y}}\right) \cdot \sin \left(\alpha_{R}-\phi_{w}\right)
\end{aligned}
$$

2.3.3. Wheel/rail creep force. Each wheel experiences lateral, longitudinal and spin creepages that are defined as relative motions between wheel and rail. The expressions of creepages on curved track are different from creepages on straight track. The expressions of the longitudinal, lateral and spin creepages on curved track for the left wheel $(i=1)$ and right wheel $(i=2)$ can be 
written as equation (9), where $r_{0}$ is the nominal rolling radius.

$$
\begin{aligned}
\gamma_{x i} & =-\frac{\Delta r_{i}}{r_{0}}+(-1)^{i} d_{0} \dot{\psi}_{w} / v-(-1)^{i} d_{0} / R \\
\gamma_{y i} & =\left(\frac{\dot{y}_{w}}{v}+\frac{r_{0} \dot{\phi}_{w}}{v}\right)-\psi_{w} \cos \left(\alpha_{i}-(-1)^{i} \phi_{w}\right) \\
\gamma_{s i} & =\frac{\left\{\begin{array}{c}
\left(\dot{\psi}_{w}-v / R\right) \cos \left(\alpha_{i}-(-1)^{i} \phi_{w}\right) \\
-(-1)^{i} v / r_{0} \sin \left(\alpha_{i}-(-1)^{i} \phi_{w}\right)
\end{array}\right\}}{v}
\end{aligned}
$$

According to Kalker's linear theory, the creep coefficients are written as equation (10),

$$
\begin{aligned}
& f_{11 i}=G m n\left(\frac{3 \pi\left(1-\sigma^{2}\right)}{2 E(A+B)} N_{i}\left(\mathbf{P}_{\mathbf{f}}, \mathbf{U}, \mathbf{V}, \mathbf{Y}, \dot{\mathbf{Y}}, \ddot{\mathbf{Y}}\right)\right)^{\frac{2}{3}} C_{11} \\
& f_{22 i}=G m n\left(\frac{3 \pi\left(1-\sigma^{2}\right)}{2 E(A+B)} N_{i}\left(\mathbf{P}_{\mathbf{f}}, \mathbf{U}, \mathbf{V}, \mathbf{Y}, \dot{\mathbf{Y}}, \ddot{\mathbf{Y}}\right)\right)^{\frac{2}{3}} C_{22} \\
& f_{23 i}=G m n\left(\frac{3 \pi\left(1-\sigma^{2}\right)}{2 E(A+B)} N_{i}\left(\mathbf{P}_{\mathbf{f}}, \mathbf{U}, \mathbf{V}, \mathbf{Y}, \dot{\mathbf{Y}}, \ddot{\mathbf{Y}}\right)\right) C_{23} \\
& f_{33 i}=G m n\left(\frac{3 \pi\left(1-\sigma^{2}\right)}{2 E(A+B)} N_{i}\left(\mathbf{P}_{\mathbf{f}}, \mathbf{U}, \mathbf{V}, \mathbf{Y}, \dot{\mathbf{Y}}, \ddot{\mathbf{Y}}\right)\right)^{\frac{4}{3}} C_{33} \\
& (A+B)=\frac{1}{2}\left(\frac{1}{R_{w}}+\frac{1}{r_{r}}+\frac{1}{r_{w}}\right)
\end{aligned}
$$

where $R_{w}, r_{w}, r_{r}, G, C_{i j}, m, n$ are the wheel-set rolling radius, transverse radius of wheel profile, transverse radius of rail profile, the shear modulus, non-dimension Kalker coefficient and coefficients about $A$ and $B$, respectively.

The creep forces and moments are calculated by equation (11), where $F_{x i}$ is the longitudinal creep force, and $F_{y i}$ is the lateral creep force.

$$
\begin{aligned}
F_{x i} & =-f_{11 i} \gamma_{x i} \\
F_{y i} & =-f_{22 i} \gamma_{y i}-f_{23 i} \gamma_{s i} \\
M_{z i} & =f_{23 i} \gamma_{y i}-f_{33 i} \gamma_{s i}
\end{aligned}
$$

In order to evaluate the wheel/rail creep forces more accurately, modifications for the creep forces in equation (11) can be made according to Shen-HedrickElkins' nonlinear creep force model (Shen et al., 1983).

$$
\begin{gathered}
F_{i}=\sqrt{F_{x i}^{2}+F_{y i}^{2}} \\
F_{i}^{\prime}= \begin{cases}f \cdot N_{i F}\left[\frac{F}{f \cdot N_{i F}}-\frac{1}{3}\left(\frac{F}{f \cdot N_{i F}}\right)^{2}+\frac{1}{27}\left(\frac{F}{f \cdot N_{i F}}\right)^{3}\right] & \left(F \leq 3 f N_{i F}\right) \\
f \cdot N_{i} F & \left(F>3 f N_{i F}\right)\end{cases}
\end{gathered}
$$

Saturation constant $\varepsilon$ is calculated by equation (14), where $N_{i F}=N_{i}\left(\mathbf{P}_{\mathbf{f}}, \mathbf{U}, \mathbf{V}, \mathbf{Y}, \dot{\mathbf{Y}}, \ddot{\mathbf{Y}}\right)$ and $f$ is the friction coefficient.

$$
\begin{aligned}
\varepsilon & =\frac{F_{i}^{\prime}}{F_{i}} \\
F_{x i}^{\prime} & =\varepsilon \cdot F_{x i} \\
F_{y i}^{\prime} & =\varepsilon \cdot F_{y i} \\
M_{x i}^{\prime} & =\varepsilon \cdot M_{z i}
\end{aligned}
$$

When equations (9-11) and equation (14) are substituted into equation (15), the creep forces and moments modified are obtained. As shown in equation (10) and (13), creep coefficients and saturation constant $\varepsilon$ are functions of normal forces $N_{i}\left(\mathbf{P}_{\mathbf{f}}, \mathbf{U}, \mathbf{V}, \mathbf{Y}, \dot{\mathbf{Y}}, \ddot{\mathbf{Y}}\right)$. It is known from equation (5) that aerodynamic loads can make the normal forces changed, so the aerodynamic loads can make the creep forces and moments changed. In addition, the equilibrium position of wheel-set changes under the aerodynamic loads, so the wheel/rail contact parameters change under the aerodynamic loads. This effect can also make creep forces and moments changed. These changes of creep forces and moments also indicate that the natural characteristics of vehicle dynamic system are changed.

\subsection{Determination of the linear critical speed}

To analyze the linear stability of railway vehicle system, the authors linearize the nonlinear dynamic equations of vehicle system at the equilibrium position. To evaluate the equilibrium position, one should consider the aerodynamic actions as steady forces, and take the effects of steady aerodynamic loads, factor of curve track and centrifugal force into account. By setting $\ddot{\mathbf{Y}}=\dot{\mathbf{Y}}=\mathbf{0}$ in equation (2), a nonlinear algebraic equation set is obtained. Then the equilibrium position $\mathbf{Y}=\mathbf{Y}_{\mathbf{0}}$ is obtained by solving the nonlinear algebraic equation set using Newton iteration.

The linearized equation at the equilibrium position can be written as equation (16).

$$
\begin{aligned}
& {\left[\begin{array}{cc}
\mathbf{M}_{1} & 0 \\
0 & 0
\end{array}\right]\left\{\begin{array}{c}
\ddot{\mathbf{Y}}_{1} \\
\ddot{\mathbf{Y}}_{2}
\end{array}\right\}+\left.\left[\begin{array}{cc}
\mathbf{C}_{1}\left(\mathbf{P}_{\mathbf{f}}, \mathbf{U}, \mathbf{V}, R, C_{0}, \mathbf{Y}, \dot{\mathbf{Y}}\right) & 0 \\
\mathbf{C}_{2} & \mathbf{C}_{3}
\end{array}\right]\right|_{\mathbf{Y}=\mathbf{Y}_{\mathbf{0}}}} \\
& \times\left\{\begin{array}{c}
\dot{\mathbf{Y}}_{1} \\
\dot{\mathbf{Y}}_{2}
\end{array}\right\}+\left.\left[\begin{array}{cc}
\mathbf{K}_{1}\left(\mathbf{P}_{\mathbf{f}}, \mathbf{U}, \mathbf{V}, R, C_{0}, \mathbf{Y}, \dot{\mathbf{Y}}\right) & \mathbf{K}_{2} \\
\mathbf{K}_{3} & \mathbf{K}_{4}
\end{array}\right]\right|_{\mathbf{Y}=\mathbf{Y}_{\mathbf{0}}}\left\{\begin{array}{l}
\mathbf{Y}_{1} \\
\mathbf{Y}_{2}
\end{array}\right\}=\mathbf{0}
\end{aligned}
$$


Equation (17) is the reduced order equation, where $\mathbf{X}=\left(\mathbf{0}, \mathbf{Y}_{\mathbf{0}}\right)$ represents the equilibrium position.

$$
\dot{\mathbf{x}}=[A] \mathbf{x}, \quad[A]=\left.\left[\frac{\partial f_{i}}{\partial x_{j}}\right]\right|_{\mathbf{x}=\left(\mathbf{0}, \mathbf{Y}_{\mathbf{0}}\right)}, \quad i, j=1,2, \ldots, 40
$$

According to the Lyapunov's indirect method, the stability of nonlinear system described by equation (2) in the neighbourhood of its equilibrium point can be determined by the eigenvalues of Jacobian matrix $A$. If all the eigenvalues have negative real parts, the system is asymptotically stable. If there is at least one eigenvalue with positive real part, the system is unstable. When the maximum real part turns to be zero, the vehicle system comes to a critical state, and the corresponding speed is the critical speed.

\section{Hunting stability of railway vehicle on a curved track considering steady aerodynamic loads}

The first section provides the analysis method of hunting stability of railway vehicle on a curved track under aerodynamic actions. On the basis of the analyses above, a computational program named AHSHSRVCT is written. In this section, the results of program verification are demonstrated in section 3.1. Considering aerodynamic loads (aerodynamic lift force, lateral force, overturning moment, pitching moment and yaw moment) in the three aerodynamic conditions, the eigenvalues, critical speed and instability mode of hunting stability during curve negotiations are evaluated using the program. Section 3.2 shows the variation of linear critical speed with curve radius and super-elevation. The influence of aerodynamic loads on the instability mode is shown in section 3.3. The results of calculation based on the experimental design are demonstrated in section 3.4.

\section{I. Program verification}

In order to verify the correctness of the program AHSHSRVCT, a comparison is made with the study of Lee and Cheng (2006). Examples of railway vehicle without aerodynamic loads on a curved track are calculated, and the variation of linear critical speed with the primary longitudinal stiffness is shown in Figure 3. The maximum relative error between the results of program and literature is $2.4 \%$, so the results are in good agreement.

The other comparison with the study of Hirotsu et al. (1999) is made, and the parameters of vehicle and rail listed in the literature are adopted. The lateral

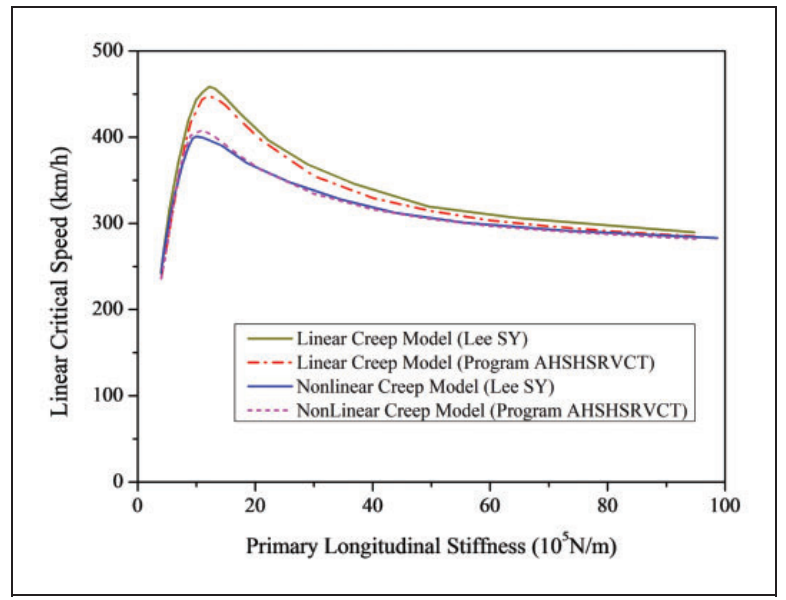

Figure 3. Comparison of critical speeds.

Table 2. Comparison of the left lateral forces of wheel/rail.

\begin{tabular}{lllll}
\hline & $\begin{array}{l}1^{\text {st }} \text { wheel- } \\
\text { set }\end{array}$ & $\begin{array}{l}2^{\text {nd }} \text { wheel- } \\
\text { set }\end{array}$ & $\begin{array}{l}3^{\text {rd }} \text { wheel- } \\
\text { set }\end{array}$ & $\begin{array}{l}4^{\text {th }} \text { wheel- } \\
\text { set }\end{array}$ \\
\hline Hirotsu T & 1889 & 1314 & 1351 & 1520 \\
AHSHSRVCT & 1889 & 1295 & 1335 & 1543 \\
Relative error & $0.0 \%$ & $1.4 \%$ & $1.2 \%$ & $1.5 \%$ \\
\hline
\end{tabular}

forces of wheel/rail at equilibrium position are evaluated, as seen in Table 2. The maximum relative error is $1.5 \%$, which reflects a good agreement. So the program is verified to be correct.

\subsection{The influence of curve radius and super- elevation on linear critical speed of railway vehicle on a curved track considering aerodynamic loads}

The correctness of program is verified in section 3.1. To investigate the influence of aerodynamic action on hunting stability of railway vehicle on a curved track, the authors calculate the linear critical speeds in the three aerodynamic conditions listed in section 2.2. During the calculation, the wind speed is $10.7 \mathrm{~m} / \mathrm{s}$, and the aerodynamic coefficients are provided by the aerodynamic research group directed by Professor Guowei Yang at Institute of Mechanics, Chinese Academy of Sciences. The critical speeds in the three aerodynamic conditions varying with curve radius and super-elevation are evaluated. Figure 4(a) shows the variation of maximum real part of eigenvalues with vehicle speed in three aerodynamic conditions, and the speed where real part equals zero is the linear critical speed. The root locus diagram of the eigenvalue corresponding to the instability mode in the three 

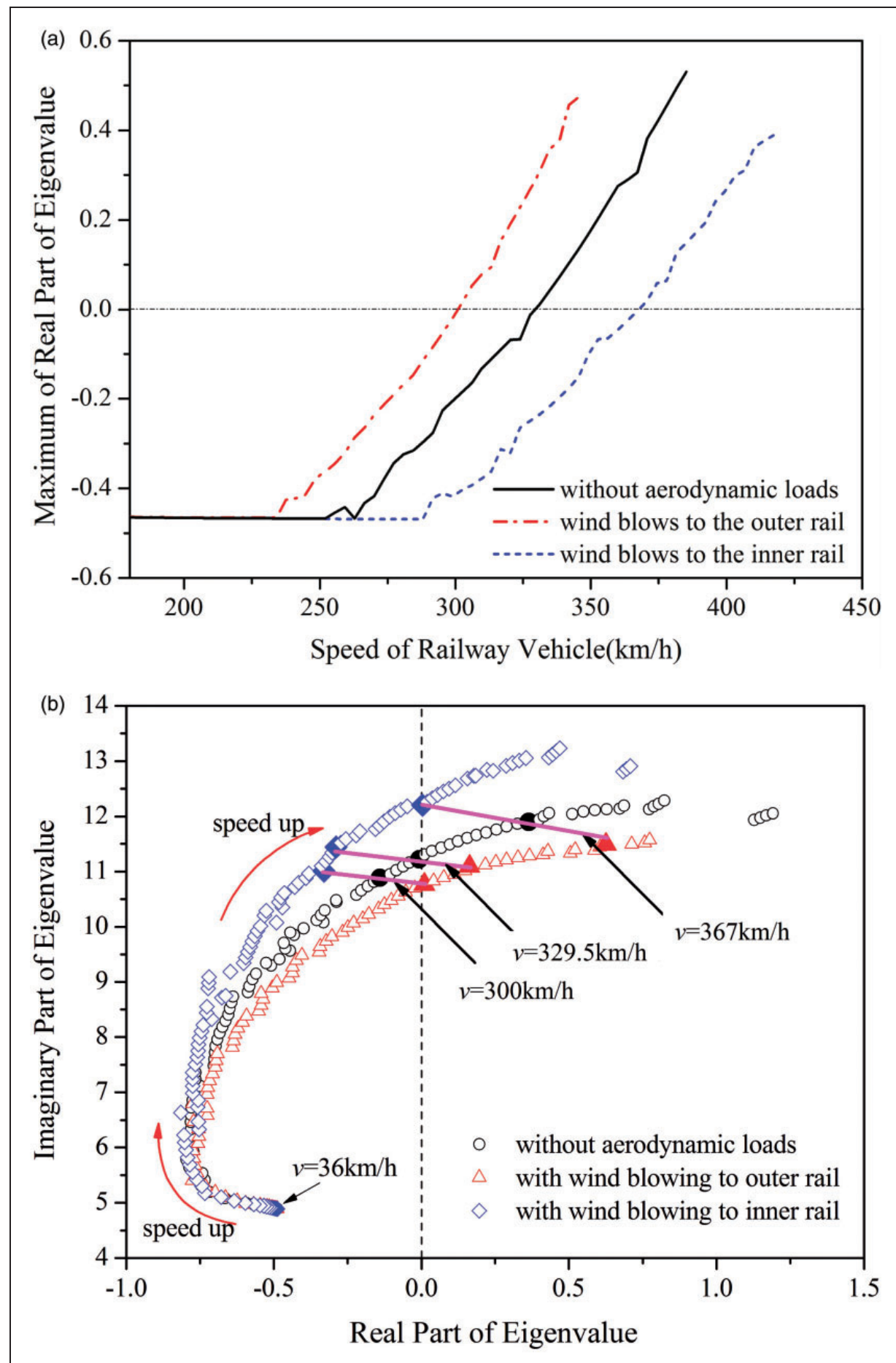

Figure 4. (a). Variation of maximum real part of eigenvalues and (b) Root locus diagram of the eigenvalue in regard to the instability mode in the three aerodynamic conditions $\left(R=6000 \mathrm{~m}, C_{0}=0.06 \mathrm{~m}\right)$.

aerodynamic conditions is shown in Figure 4(b). As shown in Figure 4(b), the aerodynamic loads make the variation tendency of the root locus changed. Compared with the case without aerodynamic loads, the real part at the same vehicle speed becomes smaller while the wind is blowing to inner rail. It means the damping of the vibration system becomes stronger, and the motion is easier to be convergence. That is to say, the system is more stable with the wind blowing to inner rail than the case without aerodynamic loads. On the contrary, the real part at the same vehicle speed becomes larger while the wind is blowing to outer 
rail. It means the damping of the vibration system becomes weaker, and the motion is harder to be convergence. It can also be seen from Figure 4(b) that the difference of eigenvalues is small when the vehicle speed is low, but obvious when the vehicle speed is high. This also explains the necessity of the study in the effects of aerodynamic loads on high-speed railway vehicle. Figure 5 is the variation of the critical speed with curve radius and super-elevation when aerodynamic loads are not considered. The cases with wind blowing to the outer rail and the inner rail are shown in Figures 6 and 7 respectively.

It is known from Figures 5-7, variation tendency of critical speed under aerodynamic actions is the same as the case without aerodynamic actions. When the curve radius is constant, the critical speed increases with the increasing of super-elevation. On the other hand, if the super-elevation is constant, the critical speed increases with the increasing of curve radius. Take the case with $R=6000 \mathrm{~m}$ and $C_{0}=0.06 \mathrm{~m}$ for example, the critical speed is $8.95 \%$ smaller than the case without aerodynamic loads when the wind blows to outer rail, and the critical speed is $11.38 \%$ larger than the case without aerodynamic loads when the wind blows to inner rail.

Based on the results from Figure 4, it is known that the critical speed decreases or increases when the wind blows to outer rail or inner rail respectively. Figure 8 shows the decreasing proportion of the critical speed for the case wind blowing to outer rail compared with the case without aerodynamic actions. When the superelevation is constant, the larger the curve radius is, the larger the decreasing proportion is. It means the aerodynamic loads of wind blowing to outer rail bring greater impact on hunting stability while the curve radius is larger. The largest reduction proportion of

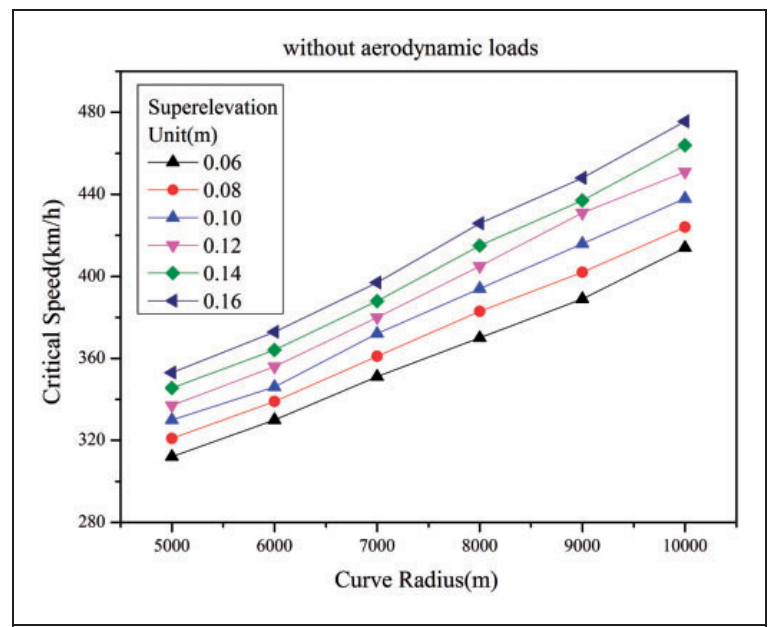

Figure 5. Variation of critical speed with curve radius and super-elevation without aerodynamic loads. critical speed $14.45 \%$ occurs when the radius is $10000 \mathrm{~m}$ and super-elevation is $0.12 \mathrm{~m}$. Figure 9 shows the increasing proportion of critical speed for the case wind blowing to inner rail compared with the case without aerodynamic action. The results in Figure 9 show that the variation of increasing proportion of critical speed with curve radius doesn't have obvious law.

\subsection{The influence of aerodynamic loads on instability mode}

Railway vehicle is a system of multi-degrees of freedom, and each degree of freedom is coupled with the others. To investigate the effects of aerodynamic loads on

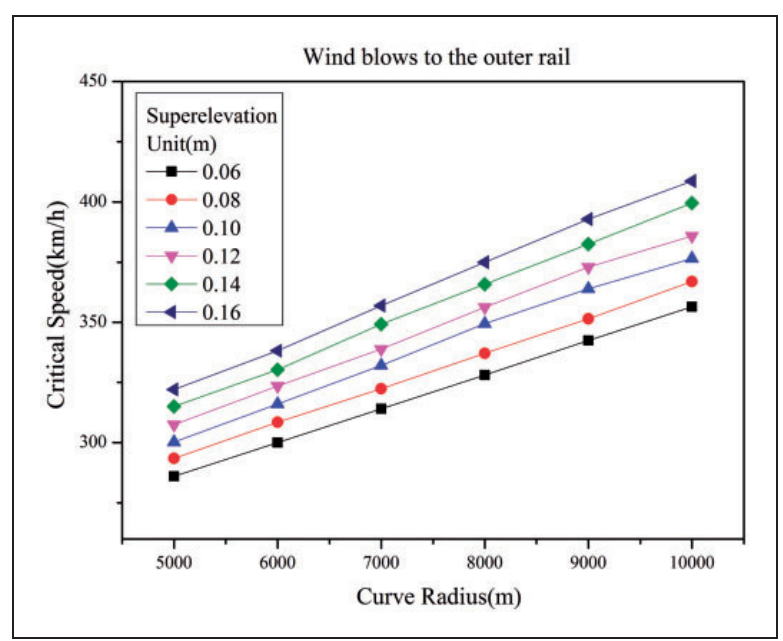

Figure 6. Variation of critical speed with curve radius and super-elevation considering wind blowing to outer rail.

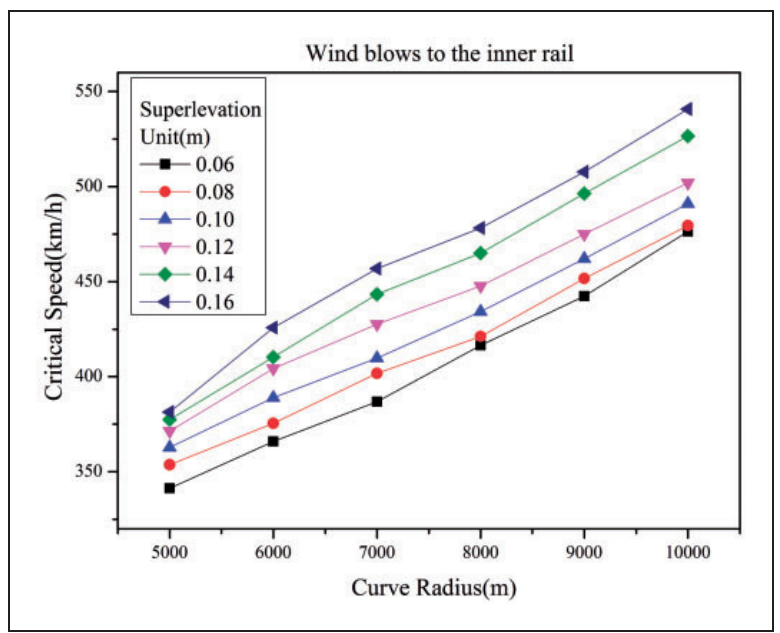

Figure 7. Variation of critical speed with curve radius and super-elevation considering wind blowing to inner rail. 


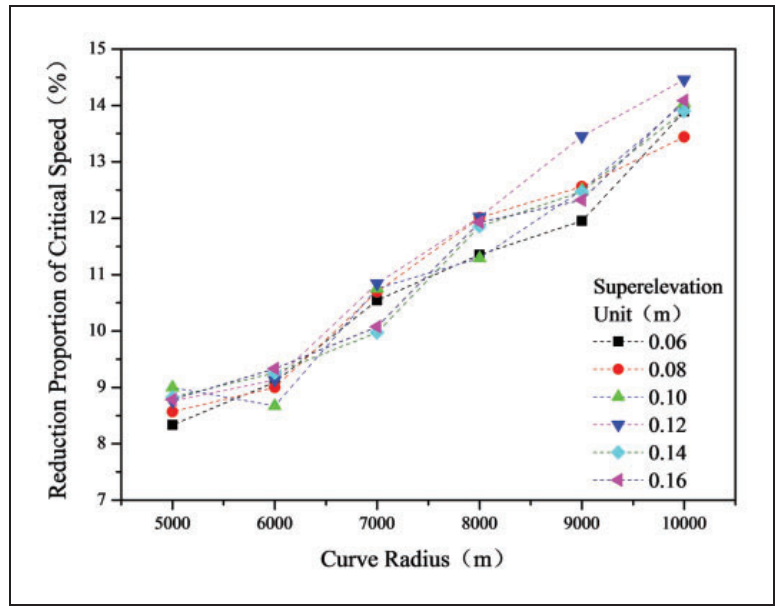

Figure 8. Decreasing proportion of critical speed for the case wind blowing to outer rail compared with the case without aerodynamic actions.

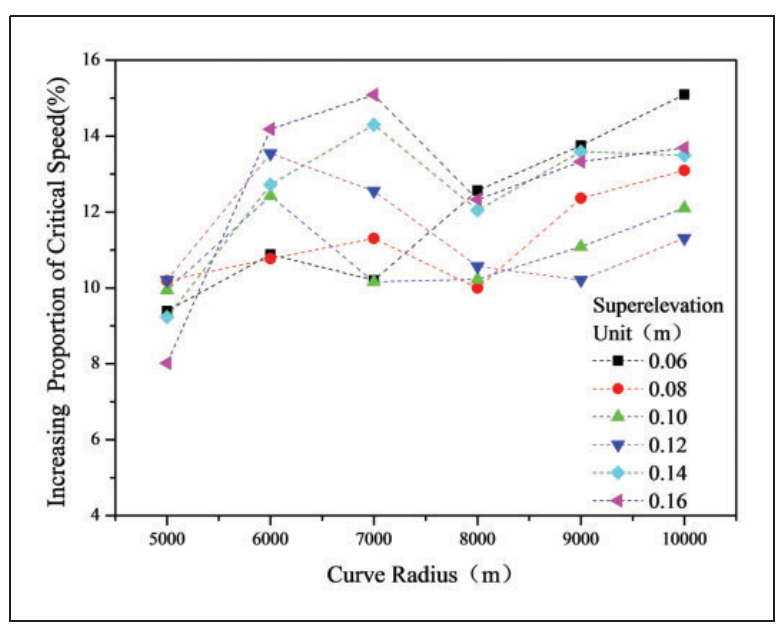

Figure 9. Increasing proportion of critical speed for the case wind blowing to inner rail compared with the case without aerodynamic actions.

critical speed of railway vehicle on a curved track, the instability modes of critical speed in the three aerodynamic conditions are evaluated by using the program AHSHSRVCT.

The parameters of simulation are as follows:

Curve radius $R=6000 \mathrm{~m}$, super-elevation $C_{0}=0.06 \mathrm{~m}$, and the critical speed of vehicle in the condition without aerodynamic actions, with wind blowing to inner rail and with wind blowing to outer rail is $329.5 \mathrm{~km} / \mathrm{h}, 367 \mathrm{~km} / \mathrm{h}$ and $300 \mathrm{~km} / \mathrm{h}$, respectively.

According to the parameters above, the eigenvalues and mode matrix of the Jacobian matrix $[A]$ in equation (17) are obtained. The displacement components of instability mode in mode matrix are analyzed. Figure 10 shows the comparison of displacement

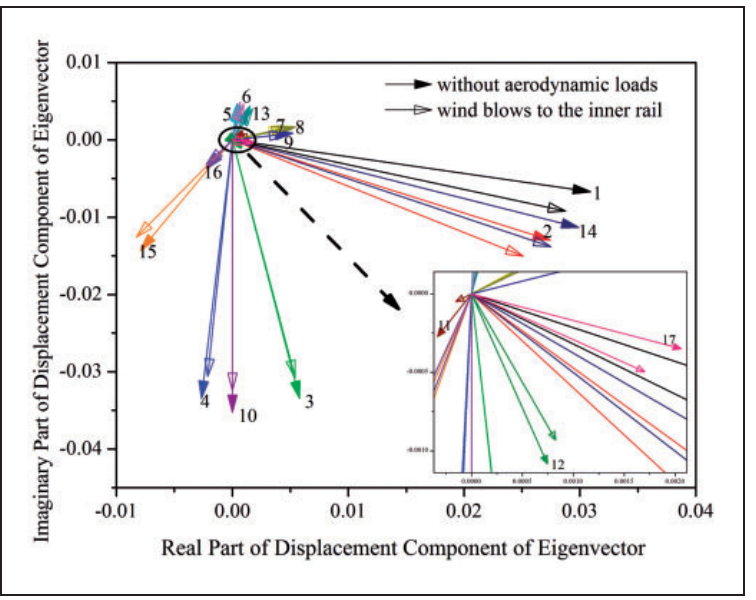

Figure 10. Comparison of displacement components of instability mode between the case with wind blowing to inner rail and the case without aerodynamic actions.

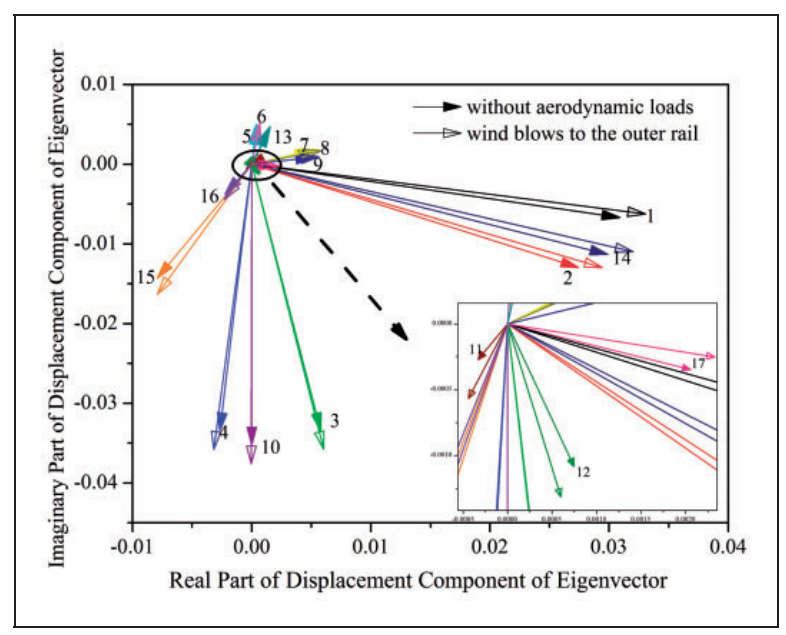

Figure II. Comparison of displacement components of instability mode between the case with wind blowing to outer rail and the case without aerodynamic actions.

components of instability mode between the case with wind blowing to inner rail and the case without aerodynamic actions. Figure 11 is the comparison between the case with wind blowing to outer rail and the case without aerodynamic actions. The moduli of displacement components of instability mode in the three aerodynamic conditions are shown in Figure 12. Figure 13 shows the variation of moduli considering aerodynamic loads in two wind directions compared with the case without aerodynamic loads. The arguments of displacement components of instability mode in the three aerodynamic conditions are shown in Figure 14. The numbers on the arrows in Figures 10-11 and horizontal ordinate in Figures 12-14 represent DOFs of the railway vehicle. 1-17 represent lateral displacement of 


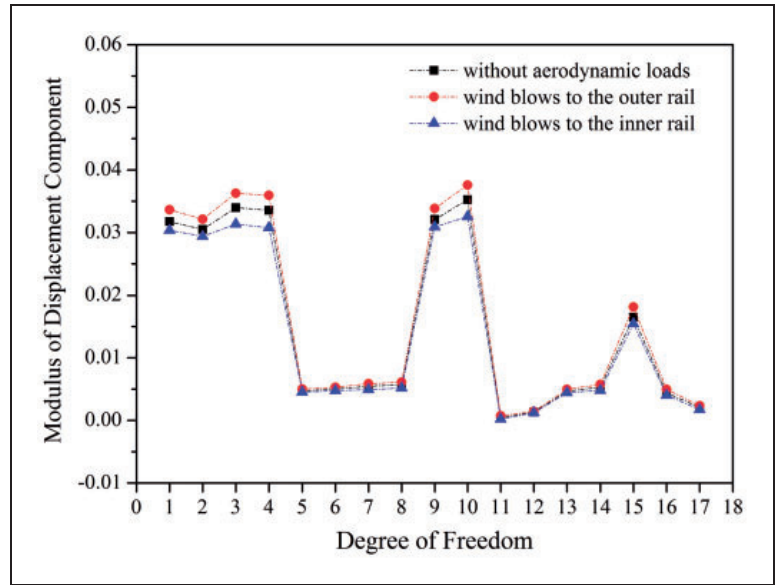

Figure 12. Moduli of displacement components of instability mode.

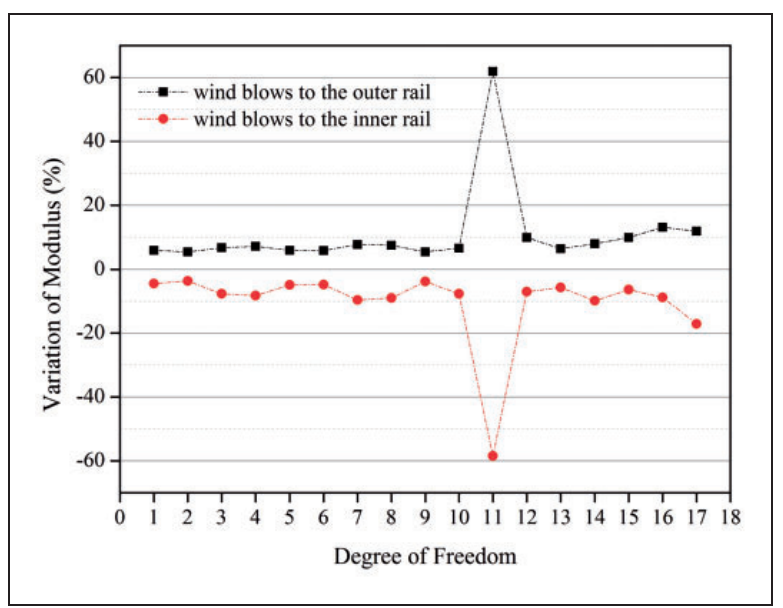

Figure 13. Variation of moduli considering aerodynamic loads.

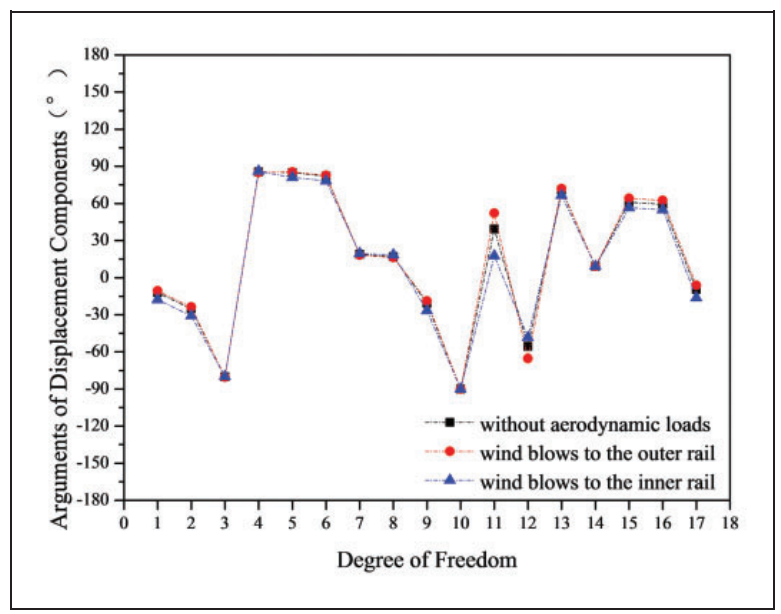

Figure 14. Arguments of displacement components of instability mode. wheel-set (1-4), yaw angle of wheel-set (5-8), lateral displacement of frame (9-10), roll angle of frame (1112), yaw angle of frame (13-14), lateral displacement, roll and yaw angle of car-body (15-17), respectively.

Through the analysis of the results above, conclusions are shown as follows.

In the three aerodynamic conditions, the moduli of lateral displacement components of wheel-set, frame and car-body are larger than the others, and the modulus of roll component of the front frame is the smallest, as shown in Figure 12. Compared with the case without aerodynamic action, all the moduli of eigenvectors decrease when the wind is blowing to inner rail, and the largest relative decreasing amplitude which is $58.5 \%$ occurs in the roll DOF of the front frame (seen in Figure 13). On the contrary, all the moduli of eigenvectors increase while the wind is blowing to outer rail, the largest relative increasing amplitude $61.9 \%$ also occurs in the roll DOF of the front frame (seen in Figure 13). It is known from the analysis that the impact on the moduli of eigenvectors is opposite when the wind direction is opposite.

Compared with the case without aerodynamic action, the arguments of lateral displacement components of the third and forth wheel-set, roll and yaw DOFs of the rear frame increase in the condition with wind blowing to inner rail, as shown in Figure 14, namely, these eigenvectors change anticlockwise, as seen in Figure 10. The arguments of other components decrease, namely, the eigenvectors change clockwise, as shown in Figures 11 and 14. While the wind is blowing to outer rail, the variation tendency of the arguments of all components are opposite with the case with wind blowing to inner rail. It is known from Figure 14, the change of argument of the eleventh component (roll of the front frame) is the biggest.

Analysis shows that the variation tendency of each module is opposite when the wind direction is different, as well as the arguments.

Assuming $\mathbf{f}$ is the instability mode, the time history at the critical speed is written as

$$
\mathbf{x}(t)=\operatorname{Re}\left\{\mathbf{f} e^{l t}\right\}
$$

where $\mathbf{f}=\left[\begin{array}{llllll}\phi_{1} & \ldots & \phi_{17} & \phi_{18} & \ldots & \phi_{34}\end{array}\right]^{T}, \phi_{1} \sim \phi_{17}$ are the velocity components of instability mode, and $\phi_{18} \sim \phi_{34}$ are the displacement components of instability. Table 3 shows the components of eigenvectors with respect to the lateral and yaw DOFs of the first two wheel-sets and front frame in instability mode.

Substituting the displacement components of eigenvectors shown in Table 3 into equation (18), the time history is drawn in Figure 15, and the effects of aerodynamic loads on instability mode is shown visually. Figure 15(a) shows the time history in the conditions 
Table 3. Components of eigenvectors with respect to the lateral and yaw DOFs of the first two wheel-sets and front frame in instability mode.

\begin{tabular}{|c|c|c|c|c|c|c|}
\hline & $\phi_{18}$ & $\phi_{22}$ & $\phi_{19}$ & $\phi_{23}$ & $\phi_{26}$ & $\phi_{30}$ \\
\hline Without aerodynamic loads & $\begin{array}{l}(0.03092 \\
-0.00668)\end{array}$ & $\begin{array}{l}(0.0004 I \\
0.00468)\end{array}$ & $\begin{array}{l}(0.02745 \\
-0.01296)\end{array}$ & $\begin{array}{l}(0.00514 \\
0.00176)\end{array}$ & $\begin{array}{l}(0.02991 \\
-0.01131)\end{array}$ & $\begin{array}{l}(0.00152 \\
0.00438)\end{array}$ \\
\hline Wind blows to the outer rail & $\begin{array}{l}(0.03308 \\
-0.00623)\end{array}$ & $\begin{array}{l}(0.00040 \\
0.00499)\end{array}$ & $\begin{array}{l}(0.02942 \\
-0.01295)\end{array}$ & $\begin{array}{l}(0.00068 \\
0.00522)\end{array}$ & $\begin{array}{l}(0.03202 \\
-0.01099)\end{array}$ & $\begin{array}{l}(0.00155 \\
0.00472)\end{array}$ \\
\hline Wind blows to the inner rail & $\begin{array}{l}(0.02877, \\
-0.00921)\end{array}$ & $\begin{array}{l}(0.00070 \\
0.00443)\end{array}$ & $\begin{array}{l}(0.025 I 0 \\
-0.0150 I)\end{array}$ & $\begin{array}{l}(0.00097 \\
0.00462)\end{array}$ & $\begin{array}{l}(0.02749 \\
-0.01379)\end{array}$ & $\begin{array}{l}(0.00175 \\
0.00403)\end{array}$ \\
\hline
\end{tabular}

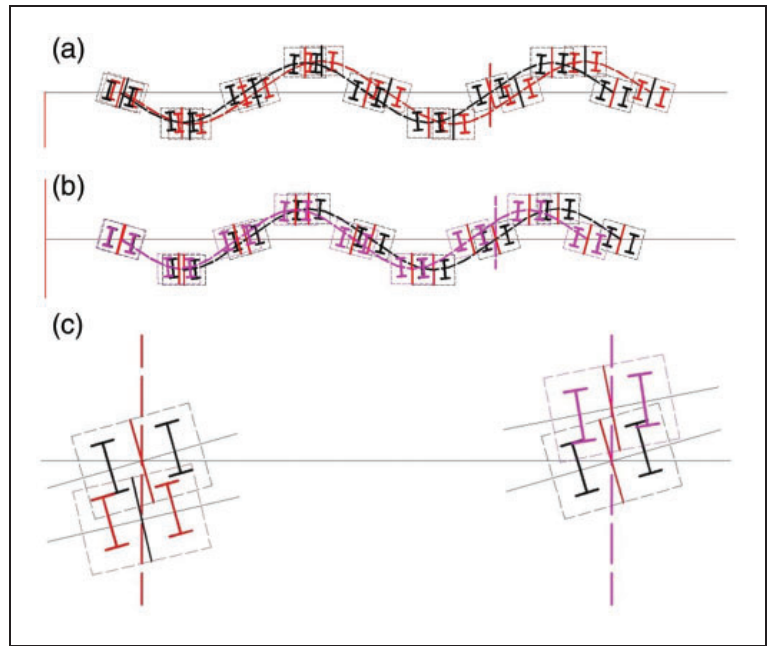

Figure 15. Time history of the front bogie in instability mode.

with wind blowing to outer rail and without aerodynamic actions. Figure 15(b) shows the time history in the conditions with wind blowing to inner rail and without aerodynamic actions. The red, pink and black line represents the time history in the condition with wind blowing to outer rail, condition with wind blowing to inner rail and condition without aerodynamic actions respectively. The displacements in Figure 15 are enlarged in proportion. Figure 15(c) shows the position when $t=0.949 \mathrm{~s}$. As for the instability mode, the displacements in the three aerodynamic conditions will vibrate in the proportion shown in Figure 15. The time history shows that the vibration frequency changes when the aerodynamic actions are considered. The vibration frequency decreases while the wind is blowing to outer rail, but increases while the wind is blowing to inner rail. Owing to the change of frequency, when $t=0.949 \mathrm{~s}$, yaw and lateral displacements of the front frame in the three aerodynamic conditions differ a lot, as shown in Figure 15(c). In addition, as for each DOF, the yaw motion has a phase difference of approximately $\pi / 2$ with the lateral motion.

\subsection{Importance analysis of factors affecting the linear critical speed using orthogonal experimental design}

Many factors can affect the linear critical speed, including aerodynamic loads, curve radius, super-elevation and suspension parameters etc. This paper is interested in the dominant factor, so the calculation based on the orthogonal experiment is performed. On the basis of orthogonal experiment method, the paper can obtain the variation of critical speed with each factor's level using fewer calculation times by reasonable combination of factors, and also find the dominant factors through the range analysis.

In this section, several important factors that affect the linear critical speed of railway vehicle on a curved track are selected to carry out orthogonal test. The 5 factors and their levels are listed in Table 4. The level $10.7 \mathrm{~m} / \mathrm{s}$ of factor 1 means that the wind speed is $10.7 \mathrm{~m} / \mathrm{s}$, and the wind blows to inner rail. On the contrary, the level $10.7 \mathrm{~m} / \mathrm{s}$ means the wind blows to outer rail. The level of zero represents the condition without aerodynamic loads. It should be noted that the aerodynamic conditions with wind speed of $5.4 \mathrm{~m} / \mathrm{s}$ are also considered in this section. The $\mathrm{L}_{25}\left(5^{6}\right)$ orthogonal array is utilized. Filling the factors and their levels in the corresponding position in the orthogonal array, as shown in Table 5, then the calculation is carried out according to the orthogonal array.

The following diagrams are drawn after processing the data in Table 5. It is easier to observe the fluctuation of index when each factor's level changes.

Figure 16 illustrates the ranges of six factors, it is seen that aerodynamic loads and curve radius are the dominant factors that affect linear critical speed. As shown in Figures 17, for all kinds of other factors' values within the interval, the linear critical speed decreases when the wind blows to outer rail, and increases when the wind blows to inner rail. As shown in Figures 18, for all kinds of other factors' values within the interval, the linear critical speed increase with the increasing of curve radius. The 
Table 4. Factors and their levels.

\begin{tabular}{|c|c|c|c|c|c|c|}
\hline & Factor I & Factor 2 & Factor 3 & Factor 4 & Factor 5 & Factor 6 \\
\hline & $\begin{array}{l}\text { Aerodynamic } \\
\text { loads }\end{array}$ & $\begin{array}{l}\text { Curve } \\
\text { radius } / \mathrm{m}\end{array}$ & Super-elevation/m & $\begin{array}{l}\text { Primary longitudinal } \\
\text { stiffness } /(\mathrm{N} / \mathrm{m})\end{array}$ & $\begin{array}{l}\text { Damping of } \\
\text { lateral damper/(N/m) }\end{array}$ & $\begin{array}{l}\text { Damping of } \\
\text { yaw damper/(N/m) }\end{array}$ \\
\hline Level I & $-10.7 \mathrm{~m} / \mathrm{s}$ & 6000 & 0.06 & 12878000 & II0544 & 230300 \\
\hline Level 2 & $-5.4 \mathrm{~m} / \mathrm{s}$ & 7000 & 0.07 & 13700000 & 117600 & 245000 \\
\hline Level 3 & 0 & 8000 & 0.08 & 14522000 & 124656 & 259700 \\
\hline Level 4 & $5.4 \mathrm{~m} / \mathrm{s}$ & 9000 & 0.09 & 15344000 & 131712 & 274400 \\
\hline Level 5 & $10.7 \mathrm{~m} / \mathrm{s}$ & 10000 & 0.10 & 16166000 & 138768 & 289100 \\
\hline
\end{tabular}

Table 5. Orthogonal array and results.

\begin{tabular}{llllllll}
\hline Test & Column I & Column 2 & Column 3 & Column 4 & Column 5 & Column 6 & Critical speed $(\mathrm{km} / \mathrm{h})$ \\
\hline 1 & 1 & 1 & 1 & 1 & 1 & 1 & 360.4 \\
2 & 1 & 2 & 2 & 2 & 2 & 2 & 375.3 \\
3 & 1 & 3 & 3 & 3 & 3 & 3 & 387.1 \\
4 & 1 & 4 & 4 & 4 & 4 & 4 & 413.0 \\
5 & 1 & 5 & 5 & 5 & 5 & 5 & 437.4 \\
6 & 2 & 1 & 2 & 3 & 4 & 5 & 338.6 \\
7 & 2 & 2 & 3 & 4 & 5 & 1 & 313.0 \\
8 & 2 & 3 & 4 & 5 & 1 & 2 & 377.0 \\
9 & 2 & 4 & 5 & 1 & 2 & 3 & 471.8 \\
10 & 2 & 5 & 1 & 2 & 3 & 4 & 462.1 \\
11 & 3 & 1 & 3 & 5 & 2 & 4 & 310.3 \\
12 & 3 & 2 & 4 & 1 & 3 & 5 & 364.2 \\
13 & 3 & 3 & 5 & 2 & 4 & 1 & 341.3 \\
14 & 3 & 4 & 1 & 3 & 5 & 2 & 338.8 \\
15 & 3 & 5 & 2 & 4 & 1 & 3 & 393.1 \\
16 & 4 & 1 & 4 & 2 & 5 & 3 & 309.4 \\
17 & 4 & 2 & 5 & 3 & 1 & 4 & 357.6 \\
18 & 4 & 3 & 1 & 4 & 2 & 5 & 347.6 \\
19 & 4 & 4 & 2 & 5 & 3 & 1 & 335.6 \\
20 & 4 & 5 & 3 & 1 & 4 & 2 & 391.6 \\
21 & 5 & 1 & 5 & 4 & 3 & 2 & 286.6 \\
22 & 5 & 2 & 1 & 5 & 4 & 3 & 326.0 \\
23 & 5 & 3 & 2 & 1 & 5 & 4 & 357.5 \\
24 & 5 & 4 & 3 & 2 & 1 & 5 & 1 \\
25 & 5 & 5 & 4 & 3 & 2 & 1 & \\
\hline
\end{tabular}

conclusions of Figures 17 and 18 are same as that in section 3.2.

Figure 19 is the dependence of the average linear critical speed on primary longitudinal stiffness. The results indicate that for all kinds of other factors' values within the interval, lager primary longitudinal stiffness can bring lower linear critical speed.

\section{Conclusions}

The aerodynamic loads can change the wheel/rail normal forces, and then change the gravitational restoring force and creep coefficients. The aerodynamic loads, curved track, centrifugal force and gyroscopic effect of wheel-set can change the equilibrium position of vehicle 


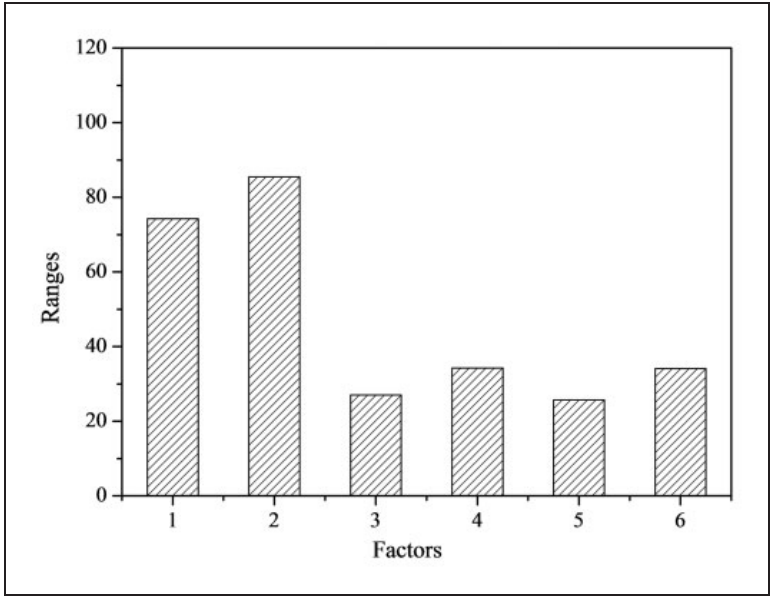

Figure 16. Ranges of factors.

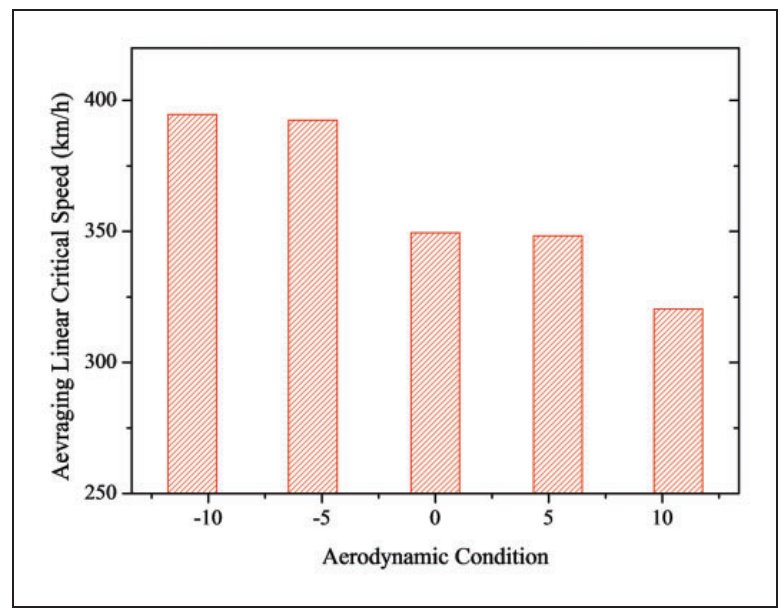

Figure 17. Variation of the average linear critical speed with aerodynamic condition.

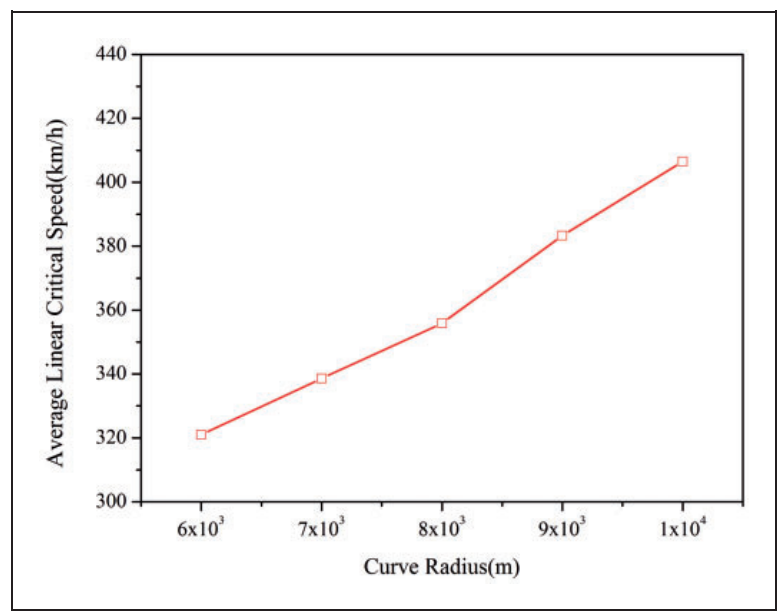

Figure I8. Variation of the average linear critical speed with curve radius.

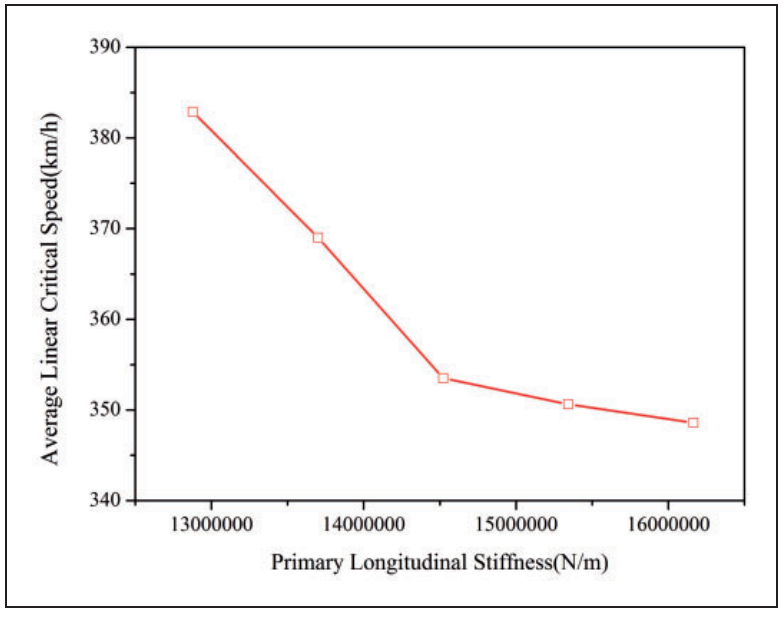

Figure 19. Variation of the average linear critical speed with primary longitudinal stiffness.

system. These effects change the natural characteristics of vehicle dynamic system. The analysis method of hunting stability considering these effects is provided in this paper. The authors evaluate the equilibrium position of vehicle running on a curved track under aerodynamic action, and linearize the dynamic equations of vehicle system at the equilibrium position. The hunting stability is analyzed through eigenanalysis of the linearized equation. The linear critical speeds of railway vehicle on a curved track in the three aerodynamic conditions are investigated. The influence of track curve radius and super-elevation on the critical speed considering aerodynamic loads is analyzed, and the influence of aerodynamic loads on instability mode is analyzed as well. In addition, the calculation based on the orthogonal experiment method is performed to analyze the importance of several factors that affect the linear critical speed. The results of calculations can be summarized as follows:

1. The critical speed decreases when the wind blows to outer rail, the critical speed increases when the wind blows to inner rail. For example, the curve radius is $6000 \mathrm{~m}$, the super-elevation is $0.06 \mathrm{~m}$, and the speed of crosswind is $10.7 \mathrm{~m} / \mathrm{s}$. When the wind blows to outer rail, the critical speed is $8.95 \%$ smaller than the case without aerodynamic loads. When the wind blows to inner rail, the critical speed is $11.38 \%$ larger than the case without aerodynamic loads.

2. Considering the curve radius in the range of $5000 \mathrm{~m}$ to $10000 \mathrm{~m}$, the aerodynamic loads of wind blowing to outer rail bring greater impact on the hunting stability when the curve radius is larger.

3. The variation tendency of linear critical speed considering aerodynamic actions is the same as the case without aerodynamic actions. The critical speed 
increases with the increasing of curve radius and super-elevation.

4. The variation tendency of the moduli of displacement components in instability mode is opposite when the wind direction is opposite, as well as the variation tendency of the arguments. If the wind direction is determined, the variation magnitude of the modulus is different from each other. Parts of the arguments become larger, the others become smaller. However, all the variation tendencies of the moduli are same for the same wind direction.

5. Aerodynamic loads can change the relative amplitude and frequency of instability mode.

6. It is known from the calculation based on the orthogonal experiment method that aerodynamic action is the dominant factor which affects the linear critical speed of railway vehicle on a curved track. This indicates that the aerodynamic loads should be taken into consideration when the hunting stability of high-speed railway vehicle is investigated. The calculation also shows that the linear critical speed decreases with the increasing of the primary longitudinal stiffness for all kinds of other factors' values within the interval.

\section{Conflict of interest}

The authors declare no conflict of interest.

\section{Funding}

This work was supported by the National Basic Research Program (973 Program) of China (2011CB711100, 2014CB046801), the National Natural Science Foundation of China (11072246, 51490673) and the Knowledge Innovation Program of Chinese Academy of Sciences (KJCX2-EW-L01).

\section{References}

Baker C, Cheli F, Orellano A, et al. (2009) Cross-wind effects on road and rail vehicles. Vehicle system dynamics 47: 983-1022.

Baker CJ (2010) The simulation of unsteady aerodynamic cross wind forces on trains. Journal of Wind Engineering and Industrial Aerodynamics 98: 88-99.

Baker C, Hemida H, Iwnicki S, et al. (2011) Integration of crosswind forces into train dynamic modelling. Proceedings of the Institution of Mechanical Engineers, Part F: Journal of Rail and Rapid Transit 225: 154-164.

Cheli F, Desideri R, Diana G, et al. (2006) Cross wind effects on tilting trains. Proceedings of the 7th World Congress on Railway Research (WCRR), Montreal, Canada, June 4-8, pp.1-12.

Cheng YC, Lee SY and Chen HH (2009) Modeling and nonlinear hunting stability analysis of high-speed railway vehicle moving on curved tracks. Journal of Sound and Vibration 324: 139-160.
Cheng YC and Lee SY (2010) Stability analysis of high-speed railway vehicle using half-car model. International Journal of Heavy Vehicle Systems 17: 139-158.

Cheng YC, Chen CH and Yang CJ (2011) Dynamics analysis of high-speed railway vehicles excited by wind loads. International Journal of Structural Stability and Dynamics 11: 1103-1118.

Cheng YC (2012) Hunting stability analysis of a railway vehicle system using a novel non-linear creep model. Proceedings of the Institution of Mechanical Engineers, Part F, Journal of Rail and Rapid Transit 226: 612-629.

Dong H, Zeng J, Xie JH, et al. (2013) Bifurcation $\backslash$ instability forms of high speed railway vehicles. Science China Technological Sciences 56: 1685-1696.

Dukkipati RV and Narayana Swamy S (2001a) Non-linear steady-state curving analysis of some unconventional rail trucks. Mechanism and Machine Theory 36: 507-521.

Dukkipati RV and Narayana Swamy S (2001b) Lateral stability and steady state curving performance of unconventional rail trucks. Mechanism and Machine Theory 36: 577-587.

Hirotsu T, Terada K, Hiraishi M, et al. (1991) Simulation of hunting of rail vehicles: The case using a compound circular wheel protile. JSME international journal. Series. 3, Vibration, Control Engineering, Engineering for Industry 3: 396-403.

Hirotsu T, Shimada M, Takaomi N, et al. (1999) Curving simulation of a non-pendulum rail vehicle: 1st Report, The influence of configurations and forced steering. The Japan Society of Mechanical Engineers(C) 65: 3531-3538.

Kim P, Jung J and Seok J (2011) A parametric dynamic study on hunting stability of full dual-bogie railway vehicle. International Journal of Precision Engineering and Manufacturing 12: 505-519.

Lee SY and Cheng YC (2005) Nonlinear analysis on hunting stability for high-speed railway vehicle trucks on curved tracks. Journal of vibration and acoustics 127: 324-332.

Lee SY and Cheng YC (2006) Influences of the vertical and the roll motions of frames on the hunting stability of trucks moving on curved tracks. Journal of Sound and Vibration 294: 441-453.

Liu H, Zeng J and Lu K (2005) A study of hopf bifurcation of hunting motion for high-speed passenger cars. Engineering Mechanics 22: 224-228.

Liu JL, Yu MG, Zhang JY, et al. (2011) Study on running safety of high-speed train under crosswind by large eddy simulation. Journal of the China Railway Society 33: $13-21$.

Mao J, Xi YH and Yang GW (2011) Research on influence of characteristics of cross wind field on aerodynamic performance of a high-speed train. Journal of the China Railway Society 4: 006.

Shen ZY, Hedrick JK and Elkins JA (1983) A comparison of alternative creep force models for rail vehicle dynamic analysis. Vehicle System Dynamics 12: 79-83.

Suzuki M, Tanemoto K and Maeda T (2003) Aerodynamic characteristics of train/vehicles under cross winds. Journal of Wind Engineering and Industrial Aerodynamics 91: 209-218. 
Wang FC and Liao MK (2010) The lateral stability of train suspension systems employing inerters. Vehicle System Dynamics 48: 619-643.

Yu MG, Zhang JY and Zhang WH (2011) Running attitudes of car body and wheelset for high-speed train under cross wind. Jiaotong Yunshu Gongcheng Xuebao 11: 48-55.

Zboinski K and Dusza M (2006) Development of the method and analysis for non-linear lateral stability of railway vehicles in a curved track. Vehicle System Dynamics 44: $147-157$.

Zboinski K and Dusza M (2008) Bifurcation approach to the influence of rolling radius modelling and rail inclination on the stability of railway vehicles in a curved track. Vehicle System Dynamics 46: 1023-1037.

Zboinski K and Dusza M (2010) Self-exciting vibrations and Hopf's bifurcation in non-linear stability analysis of rail vehicles in a curved track. European Journal of MechanicsA/Solids 29: 190-203.
Zboinski K and Dusza M (2011) Extended study of railway vehicle lateral stability in a curved track. Vehicle Systme Dynamics 49: 789-810.

Zeng J and Xu T (1994) Nonlinear lateral stability analysis of passenger coach system using bifurcation method. Journal of Southwest Jiaotong University 29: 316-322.

Zeng J (1996) Simulation of hunting bifurcation and limit cycle of railway vehicle system. Jouranl of the China Railway Society 18: 13-19.

Zeng J (2001) Numerical analysis of nonlinear stability for railway passenger cars. Chinese Journal of Mechanical Engineering(English Edition) 14: 97-101.

Zeng J and Wu PB (2004) Stability analysis of high speed railway vehicles. JSME International Journal Series C 47: 464-470.

Zeng XH and Lai J (2013) Hunting stability of high-speed railway vehicle considering the actions of steady aerodynamic loads. Engineering Mechanics 30: 52-58. 